\title{
Tailoring treatment for women with heavy menstrual bleeding
}

Citation for published version (APA):

Beelen, P. (2021). Tailoring treatment for women with heavy menstrual bleeding. [Doctoral Thesis, Maastricht University]. Ridderprint. https://doi.org/10.26481/dis.20210507pb

Document status and date:

Published: 01/01/2021

DOI:

10.26481/dis.20210507pb

Document Version:

Publisher's PDF, also known as Version of record

\section{Please check the document version of this publication:}

- A submitted manuscript is the version of the article upon submission and before peer-review. There can be important differences between the submitted version and the official published version of record.

People interested in the research are advised to contact the author for the final version of the publication, or visit the DOI to the publisher's website.

- The final author version and the galley proof are versions of the publication after peer review.

- The final published version features the final layout of the paper including the volume, issue and page numbers.

Link to publication

\footnotetext{
General rights rights.

- You may freely distribute the URL identifying the publication in the public portal. please follow below link for the End User Agreement:

www.umlib.nl/taverne-license

Take down policy

If you believe that this document breaches copyright please contact us at:

repository@maastrichtuniversity.nl

providing details and we will investigate your claim.
}

Copyright and moral rights for the publications made accessible in the public portal are retained by the authors and/or other copyright owners and it is a condition of accessing publications that users recognise and abide by the legal requirements associated with these

- Users may download and print one copy of any publication from the public portal for the purpose of private study or research.

- You may not further distribute the material or use it for any profit-making activity or commercial gain

If the publication is distributed under the terms of Article $25 \mathrm{fa}$ of the Dutch Copyright Act, indicated by the "Taverne" license above, 


\section{Chapter 9.}

Summary 


\section{Chapter 9}

Heavy menstrual bleeding (HMB) affects around 30\% of women at some time during their reproductive years making it a common reason for gynaecological consultations in both primary and secondary care. It has a negative impact on a woman's quality of life, influencing physical, emotional, sexual and social wellbeing. In view of its high prevalence and major impact on quality of life, effective treatment is important.

In most women with HMB no underlying pathology is found and various treatment options can be considered to reduce the amount of menstrual bleeding, including pharmacological and surgical treatments. Pharmacological treatments include non-hormonal therapies: tranexamic acid or non-steroidal anti-inflammatory drugs (NSAIDs), and hormonal therapies: progestogens, combined hormonal contraception and the levonorgestrel-releasing intrauterine system (LNG-IUS). The LNG-IUS has been shown to be more effective in the treatment of HMB compared to oral medication. Nevertheless, around $40 \%$ of women discontinue the LNG-IUS within two years, because of a lack of effectiveness or side effects. Alternative surgical treatments include endometrial ablation and hysterectomy. While hysterectomy is a definitive solution, it is also an invasive option, with a risk of serious complications. Endometrial ablation is a minimally invasive alternative that aims to destroy or remove the endometrial tissue with high satisfaction rates and reported reintervention rates around $10-20 \%$.

In daily practice both endometrial ablation and LNG-IUS are frequently used treatments in women with HMB. Because of limited evidence, these is no evidencebased advice regarding the preference for either LNG-IUS or endometrial ablation.

This thesis focuses on the effectiveness of the LNG-IUS compared to endometrial ablation, including the cost-effectiveness. Furthermore, it provides insight in patient preference and investigates prognostic factors for failure of both LNG-IUS and endometrial ablation.

Chapter 1 outlines the aim of this thesis, and is formulated in four questions:

1. Do women with heavy menstrual bleeding prefer a treatment with LNG-IUS or endometrial ablation?

2. What is the effectiveness of LNG-IUS compared to endometrial ablation in women with heavy menstrual bleeding?

3. Which treatment strategy is cost-effective, LNG-IUS or endometrial ablation?

4. Is it possible to predict failure of both LNG-IUS and endometrial ablation based upon prognostic factors? 


\section{Do women with heavy menstrual bleeding prefer a treatment with LNG-IUS or endometrial ablation?}

To answer this question, we conducted a discrete choice experiment which is described in chapter $\mathbf{2}$. In this study we investigated whether women with HMB have a preference for treatment characteristics of the LNG-IUS or endometrial ablation. The study was performed in general practices and at the outpatient gynaecology departments of two hospitals in the Netherlands. Women with HMB were asked to choose between hypothetical profiles containing characteristics of LNG-IUS or endometrial ablation. Characteristics included: (1) procedure performed by gynaecologist or general practitioner; (2) reversibility of the procedure; (3) probability of dysmenorrhea; (4) probability of irregular bleeding; (5) use of additional contraception; (6) need to repeat the procedure after five years; (7) treatment containing hormones. The main outcome measures were the relative importance of the characteristics and willingness to make trade-offs between the characteristics. In total 165 women completed the questionnaire and the characteristic which was found the most important was whether a treatment contains hormones. Women preferred a treatment without hormones, a treatment with the least side effects, and no need for a repeat procedure or additional contraception. Women completing the questionnaire at the gynaecology outpatient clinic differed from women in general practice in their preference for a definitive treatment which is performed by a gynaecologist. In conclusion participants preferred characteristics that were mostly related to endometrial ablation, but were willing to trade-off between the different characteristics.

\section{What is the effectiveness of the LNG-IUS compared to endometrial ablation}

Chapter 3 and 4 focuses on this question.

Chapter 3 presents the results of a multicentre randomised controlled noninferiority trial comparing the effectiveness of the LNG-IUS (Mirena ${ }^{\circledR}$ ) to bipolar radiofrequency endometrial ablation (NovaSure ${ }^{\circledR}$ ) in women with $\mathrm{HMB}$. The trial was performed in 26 hospitals and in a network of general practices in the Netherlands. Women aged 34 years and older, with HMB and no future pregnancy wish or intracavitary pathology were randomised to a treatment strategy starting with either the LNG-IUS or endometrial ablation. The primary outcome was blood loss at 24 months, measured with a Pictorial Blood Assessment Chart (PBAC)-score, with a non-inferiority margin of 25 PBAC points. Secondary outcomes included reintervention rates, patient satisfaction, quality of life, and sexual function. A total of 270 women were included in the trial, of which 132 women were allocated to the LNG-IUS (baseline PBAC-score 616 points) and 138 women to endometrial ablation (baseline PBAC-score 630 points). At 24 months a large decrease in 


\section{Chapter 9}

menstrual bleeding was seen in both groups with mean PBAC-scores of 64.8 in the LNG-IUS group and 14.2 in the endometrial ablation group (difference 50.5 points, 95\% confidence interval $[\mathrm{Cl}] 4.3$ to 96.7 , non-inferiority p-value $=0.87$ ). In the LNGIUS group 49 women (39\%) removed the intrauterine system before the end of the study. 44 women (35\%) in the LNG-IUS group underwent a reintervention (oral medication, endometrial ablation and/ or hysterectomy), compared to 27 women (20\%) in the endometrial ablation group (relative risk [RR] 1.77; 95\% Cl 1.17 to 2.68). The most important reason for receiving a reintervention was persistence of $\mathrm{HMB}$. No significant differences were found in hysterectomy rate, patient satisfaction, quality of life and sexual functioning between the groups.

This study concludes both the LNG-IUS and endometrial ablation strategy lead to a large decrease in menstrual bleeding, with comparable satisfaction and quality of life scores after 24 months. Nevertheless, endometrial ablation results in the least amount of menstrual blood loss and non-inferiority of a strategy starting with the LNG-IUS could not be demonstrated. Women who start with the LNG-IUS were shown to more frequently need further treatment to achieve the desired effect, with a quarter of women undergoing endometrial ablation. The results of this study will enable physicians to provide women with $\mathrm{HMB}$ with clear information about the effectiveness of two frequently applied HMB treatments. Women should weigh the benefits in effectiveness of endometrial ablation, against the less-invasive and reversible character of the LNG-IUS, after which a well-informed decision can be made.

An important difference we found in the RCT was the number of reinterventions (35\% of women in the LNG-IUS group versus $20 \%$ in the endometrial ablation group). A substantial part of women declined to participate in the RCT because of a preference for one of both treatments. These women were asked to participate in an observational cohort. As previous research showed increased satisfaction rates with better clinical outcomes if a patient is more involved in the choice of treatment and receives the treatment he or she prefers, we hypothesised that women in the observational cohort have lower reintervention rates compared to women in the RCT. In chapter $\mathbf{4}$ we report the reintervention rates of the women who were followed in the observational cohort and we compare the difference in reintervention rate between women in the cohort and women in the RCT. Women in the observational cohort followed the same protocol as women in the RCT. The primary outcome measure of this study was reintervention rate at 24 months of follow-up. Two hundred and seventy-six women were followed in the observational cohort of which 87 women preferred an initial treatment with LNG-IUS and 189 women preferred a treatment with endometrial ablation. At 24 months of follow-up women in the LNG-IUS-group were more likely to receive a reintervention compared to women in the ablation group, 28/81 (35\%) versus 25/178 (14\%) (RR 2.42, Cl 1.47 to 3.98). No differences in reintervention rates were 
found between women in the observational cohort and women in the RCT. These findings endorse the findings of the RCT and show women who receive an LNGIUS are more likely to undergo an additional intervention compared to women who receive endometrial ablation, with comparable reintervention rates between women in the cohort and in the RCT.

\section{Which treatment strategy is cost-effective, LNG-IUS or endometrial ablation?}

The direct medical costs for the LNG-IUS are lower compared to endometrial ablation, though a considerable part of women who receive the LNG-IUS undergo a reintervention. To determine the total costs of the LNG-IUS strategy and compare this to the endometrial ablation strategy we performed a cost-effectiveness analysis which is presented in chapter $\mathbf{5}$. For this analysis we used the effectiveness results of the RCT described in chapter 3. The PBAC was used for the assessment of effect, with the primary outcome for effectiveness being menstrual blood loss after 24 months measured with the PBAC-score. For the assessment of costs both direct medical and direct- and indirect non-medical costs were included in the analysis. The incremental cost-effectiveness ratio (ICER) for both treatment strategies was calculated based upon menstrual blood loss and the average costs per patient over a 24 months' time horizon. Total costs were $€ 2,285$ in the LNG-IUS strategy and $€ 3,465$ in the endometrial ablation strategy (difference: $€ 1,180$ ). At 24 months the strategy starting with the LNG-IUS was less effective (mean difference: 50.5 PBAC points) and less costly (-€1,180;95\% Cl -€2,097 to -€1,111) compared to the strategy starting with endometrial ablation. Endometrial ablation costed $€ 23$ per additional PBAC-point reduction of menstrual blood loss (ICER: $€ 23 ; 95 \% \mathrm{CI} € 5$ to $€ 111)$. The ICER increased to $€ 28$ under the assumption that all LNG-IUS insertions were performed in primary care and decreased to $€ 22$ under the assumption that all endometrial ablations were performed at the outpatient department with local anaesthesia. The results indicate that a strategy starting with the LNG-IUS is cheaper, but slightly less effective in menstrual blood loss reduction compared to endometrial ablation. Depending on the success rate women are willing to accept, the LNG-IUS could be a cost-effective treatment option.

\section{Is it possible to predict failure of LNG-IUS and endometrial ablation based upon prognostic factors?}

The RCT in chapter 3 showed both the LNG-IUS and endometrial ablation are not a $100 \%$ successful in treating HMB. To predict which women are at risk of treatment failure, it is important to examine if certain patient characteristics influence the effectiveness. 


\section{Chapter 9}

Chapter 6 reports a systematic review and meta-analysis on prognostic factors predicting failure of endometrial ablation in women with HMB. All types of studies reporting about prognostic factors of non-hysteroscopic endometrial ablation failure were included. The primary outcome was surgical reintervention rate (reablation and/ or hysterectomy). Fifty-six studies with a total of 157,830 women (study sizes ranging from 40 to 114,910 women) and a follow-up ranging from 12 to 120 months were included. We evaluated 10 prognostic factors: age, myomas, history of tubal ligation, body mass index, parity, pre-existing dysmenorrhea, caesarean delivery, bleeding pattern, uterus position, and uterus length. Younger age (aged 35 years or younger, odds ratio [OR] 1.68, 95\% Cl 1.19 to 2.36; aged 40 years or younger, OR $1.58,95 \% \mathrm{Cl} 1.30$ to 1.93 ; aged 45 years or younger OR $1.63,95 \% \mathrm{Cl} 1.28$ to 2.07 ), prior tubal ligation (OR $1.46,95 \% \mathrm{Cl} 1.23$ to 1.73 ), and pre-existing dysmenorrhea (OR $2.12,95 \% \mathrm{Cl} 1.41$ to 3.19 ) were associated with an increased risk of receiving a surgical reintervention. It is important to take the results of this review into account when counselling women with HMB. Women with one or more of these prognostic factors should be informed about the higher risk of failure, and alternative treatment might be considered.

Chapter 7 studies factors potentially associated with failure of LNG-IUS treatment in women with HMB. For this study data of the LNG-IUS arm of both the RCT and the observational cohort were used, described in respectively chapter 3 and 4 . Eight potential prognostic variables (age, body mass index, caesarean section, vaginal delivery, previous treatment, anticoagulant use, dysmenorrhea, and pictorial blood assessment score) were analysed using univariable and multivariable regression models to estimate the risk of failure. The main outcome measure was discontinuation of the LNG-IUS within 24 months of follow-up, defined as removal of the LNG-IUS or receiving an additional intervention. A total of 201 women were included in the analyses. 93 women (46\%) discontinued LNG-IUS treatment within 24 months. Multivariable analysis showed younger age (aged 45 years or younger, RR 1.51, 95\% Cl 1.10 to 2.09) and severe dysmenorrhea (RR 1.36, 95\% Cl 1.01 to 1.82 ) to be associated with a higher risk of discontinuation. The results can be used in the counselling of women with HMB. For future research, an analysis in a larger study population might be performed to identify additional prognostic factors for LNG-IUS failure. Furthermore, future research comparing differences between prognostic factors for the different treatment options for HMB might be helpful to further personalize counselling.

Chapter $\mathbf{8}$ provides a general discussion, clinical implications and suggestions for future research.

The studies in this thesis report on multiple important outcomes for HMB treatment, contributing to tailoring treatment to the individual woman. It is shown that both 
LNG-IUS treatment and endometrial ablation lead to a large decrease in menstrual bleeding, with comparable satisfaction and quality of life scores. Endometrial ablation has some benefits in effectiveness over LNG-IUS as it has a greater reduction in menstrual blood loss and the risk of receiving a reintervention is lower. Furthermore, it was shown that women generally preferred characteristics that were related to endometrial ablation, with a treatment without hormones being the most important characteristic. However, women were willing to make trade-offs and the LNG-IUS has some benefits over endometrial ablation as it is less invasive, it can be performed by the general practitioner and has a contraceptive effect. Besides paying attention to women's personal preferences, it is also important to take into account the presence of prognostic factors. A younger age and dysmenorrhea have been shown to be risk factors for failure for both the LNG-IUS and endometrial ablation. Prior tubal ligation additionally was a risk factor for failure of endometrial ablation. Taking all this information into consideration will improve the shared decision-making process of women with HMB. 


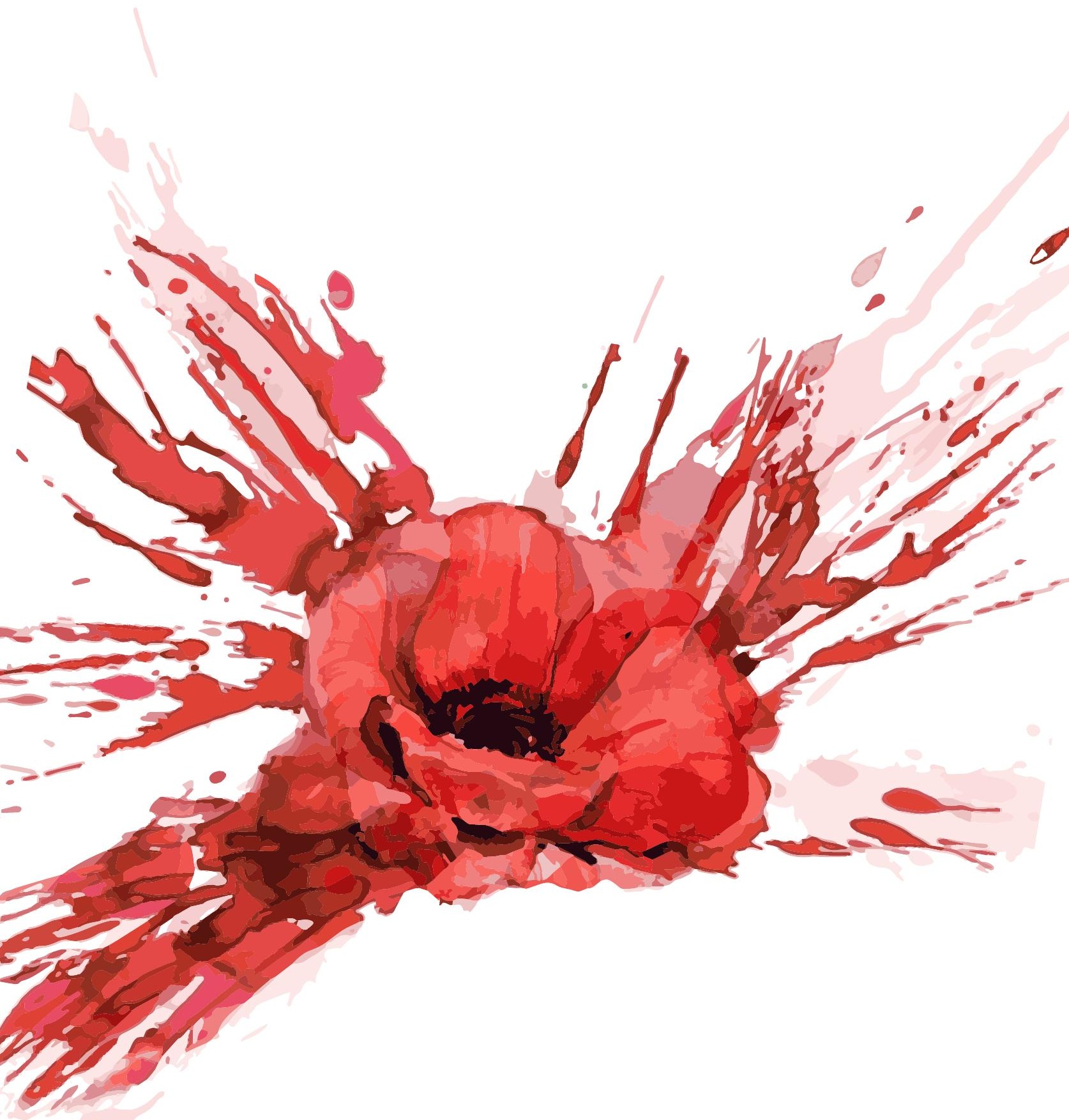

